\title{
PENGARUH GROUP INVESTIGATION DENGAN PENDEKATAN JELAJAH ALAM SEKITAR TERHADAP HASIL BELAJAR SISWA SMAN 16 PEKANBARU
}

\author{
Rikizaputra $^{1)}$ Ira Lestari $^{2)}$ \\ ${ }^{1)}$,2) Pendidikan Biologi FKIP Universitas Lancang Kuning \\ Email $^{2)}$ : rikizaputra@gmail.com \\ Email $^{2}:$ iralestari454@gmail.com
}

\begin{abstract}
ABSTRAK : Biologi merupakan salah satu mata pelajaran yang terkesan sulit dan membosankan bagi para siswa, apalagi jika dalam proses pembelajarn tidak menggunakan model ataupun pendekatan pembelajaran. Penelitian ini bertujuan untuk mengetahui pengaruh model pembelajaran Group Investigation dengan pendekatan Jelajah Alam Sekitar terhadap hasil belajar siswa pada materi Plantae. Penelitian ini dilaksanakan pada tanggal 15 November 2018 sampai 3 Desember 2018 di SMA Negeri 16 Pekanbaru semester ganjil pada tahun 2018/2019. Penelitian ini menggunakan nonequivalent pretest-posttest control group design. Sampel penelitian adalah siswa kelas X IPA 1 dan X IPA 2 dengan jumlah siswa 74 orang, yang diambil dengan teknik total sampling. Pengumpulan data dilakukan melalui pretest, posttest dan lembar aktivitas guru dan siswa. Analisis data menggunakan independent 2 sample t-test. Rerata $N$-gain pada kelas kontrol 0,52 dengan (kategori sedang) dan pada kelas eksperimen 0,67 (kategori sedang). Hasil uji-t $N$-gain menunjukkan terdapat perbedaan yang signifikan antara kelas kontrol dan kelas eksperimen. Dengan demikian dapat disimpulkan bahwa penerapan model pembelajaran Group Investigation dengan pendekatan Jelajah Alam Sekitar berpengaruh terhadap hasil belajar siswa pada materi Plantae.
\end{abstract}

Kata kunci : group investigation, jelajah alam sekitar, hasil belajar, plantae

ABSTRACT : Biology is one of the subjects that seems difficult and boring for students, especially if the learning process does not use approach or learning model. The purpose of this research was to find out the influence of the Group Investigation learning model with the Approach to the Natural Exploration Around to student learning achievement in the Plantae matery. This research was conducted on 15 November 2018 to 3 December 2018 in SMA 16 Pekanbaru at odd semester in 2018/2019. This research used a non-equivalent pretest-posttest control group design. The study sample was students of class X IPA 1 and X IPA 2 with 74 students, taken by total sampling technique. Data collection was done through pretest, posttest and teacher and student activity sheets. Data analysis using independent 2 sample t-test. The mean N-gain in the control class was 0.52 with (medium category) and in the experimental class 0.67 (medium category). The results of the $N$-gain $t$-test showed that there were significant differences between the control class and the experimental class. Thus it can be concluded that the application of the Group Investigation learning model with the Surrounding Natural Exploration approach influences student learning achievement in the Plantae matery.

Keywords : group investigation, natural exploration around, learning achievement, plantae

Bio-Lectura: Jurnal Pendidikan Biologi, Vol 6, No 2, Oktober 2019 


\section{PENDAHULUAN}

Pendidikan merupakan hal yang sangat penting dan tidak dapat dipisahkan dari kehidupan seseorang, baik dalam keluarga, masyarakat, dan bangsa. Kemajuan suatu bangsa ditentukan oleh tingkat keberhasilan pendidikan. Keberhasilan pendidikan akan dicapai suatu bangsa apabila ada usaha untuk meningkatkan mutu pendidikan bangsa itu sendiri.

Pendidikan adalah usaha yang dilakukan dengan sengaja dan sistematis untuk memotivasi, membina, membantu, serta membimbing seseorang untuk mengembangkan segala potensinya sehingga ia mencapai kualitas diri yang lebih baik. Inti pendidikan adalah usaha pendewasaan manusia seutuhnya, baik oleh dirinya sendiri maupun orang lain, dalam arti tuntutan agar anak didik memiliki kemerdekaan berpikir, merasa, berbicara, dan bertindak serta percaya diri dengan penuh rasa tanggung jawab dalam setiap tindakan dan perilaku sehari-hari (Basri dalam Tatang, 2012).

Berdasarkan informasi dari guru mata pelajaran biologi, serta pengamatan selama Praktek Pengalaman Lapangan (PPL) di SMAN 16 Pekanbaru bahwa dalam proses pembelajaran biologi, siswa kurang aktif dan kurang tertarik dalam mengikuti pelajaran. Kurangnya perhatian siswa juga terlihat dari rendahnya antusias siswa dalam bertanya maupun menjawab pertanyaan saat guru memberikan kesempatan. Dalam proses pembelajaran yang dilakukan, guru jarang memanfaatkan media dalam menjelaskan dan memberi contoh nyata ketika pembelajaran biologi berlangsung, guru juga cenderung menggunakan metode ceramah sehingga tidak memaksakan siswa untuk terlibat aktif dalam pembelajaran.

Salah satu dampak dari kondisi yang ditemukan peneliti bahwa rata-rata hasil ujian tengah semester (UTS) kelas $\mathrm{X}$ mata pelajaran biologi yang dicapai siswa masih dibawah kriteria ketuntasan minimum (KKM) yaitu 75. Adapun jumlah siswa kelas $\mathrm{X}$ sebanyak 74 orang. Hasil belajar menunjukkan 25 siswa dengan perolehan nilai $\geq 75$ dengan persentase $34 \%$ dinyatakan tuntas dalam belajar dan 49 siswa dengan persentase $66 \%$ yang memperoleh nilai $\leq 75$ dinyatakan belum tuntas dalam belajar. 
Penelitian ini bertujuan untuk mengetahui pengaruh model Group Investigation (GI) dengan pendekatan jelajah alam sekitar terhadap hasil belajar siswa pada materi Plantae kelas X SMAN 16 Pekanbaru TP 2018/2019.

\section{METODE PENELITIAN}

Penelitian ini merupakan penelitian kuasi eksperimen yang bertujuan untuk mengetahui pengaruh variabel bebas terhadap variabel terikat, menggunakan metode the matching only pretestposttest control grup desaign.
Populasi penelitian ini adalah siswa kelas X SMAN 16 Pekanbaru yang terdiri dari kelas X IPA 1 dan X IPA 2. Kedua populasi dijadikan sampel yaitu kelas X IPA 1 dan X IPA 2. Pengambilan sampel menggunakan total sampling, yang artinya semua kelas dijadikan sampel dengan jumlah 74 siswa.

Parameter dalam penelitian ini yaitu hasil belajar siswa, aktivitas guru dan aktivitas siswa.

\section{HASIL DAN PEMBAHASAN}

Berdasarkan hasil penelitian yang telah dilakukan pada tanggal 15 November - 3 Desember 2018 di kelas X IPA 1 sebagai kelas eksperimen dan X IPA 2 sebagai kelas kontrol diperoleh rekapitulasi data sebagai berikut :

Tabel 1: Rekapitulasi Hasil Uji Normalitas N-gain

\begin{tabular}{|l|l|l|l|l|}
\hline Kelas & Sig. & $\alpha$ & Keputusan & Keterangan \\
\hline Kontrol & 0.151 & 0.05 & Terima $\mathrm{H}_{0}$ & Normal \\
\hline Eksperimen & 0.200 & 0.05 & Terima $\mathrm{H}_{0}$ & Normal \\
\hline
\end{tabular}

Berdasarkan Tabel 1 dapat dilihat bahwa uji normalitas $\mathrm{N}$-gain pada kelas kontrol dan kelas eksperimen dengan taraf signifikan $(\alpha) 0.05$ diperoleh nilai signifikan untuk kelas kontrol $0.151>$ 0.05 sedangkan nilai signifikan kelas eksperimen $0.200>0.05$ yang artinya data berdistribusi normal.

Data N-gain yang berdistribusi normal selanjutnya dilakukan uji homogenitas data N-gain. Uji homogenitas ini berguna untuk mengetahui homogenitas varian data. Analisis data uji homogenitas menggunakan uji Levene test. Hasil uji homogenitas kelas kontrol dan kelas eksperimen dapat dilihat pada tabel dibawah ini : 
Tabel 2: Rekapitulasi Hasil Uji Homogenitas N-gain

\begin{tabular}{|l|l|l|l|l|}
\hline Jenis data & Based on trimmed mean & $\alpha$ & Keputusan & Keterangan \\
\hline$N$-gain & 0.164 & 0.05 & Terima $\mathrm{H}_{0}$ & Homogen \\
\hline
\end{tabular}

Berdasarkan Tabel 2 dapat dilihat hasil uji homogenitas nilai based on trimmed mean pada Tabel Levene test 0.164 dengan taraf signifikan 0.05, keputusan yang diperoleh adalah Terima $\mathrm{H}_{0}$. Artinya data $\mathrm{N}$-gain kelas kontrol dan kelas eksperimen berasal dari varian yang homogen.

Setelah diketahui data N-gain berdistribusi normal dan memiliki varian yang homogen, maka dapat diambil keputusan untuk melakukan uji hipotesis komparatif untuk mengetahui perbedaan $\mathrm{N}$-gain kelas kontrol dan kelas eksperimen dengan menggunakan uji-t Independent 2 Samples. Hasil uji-t data N-gain dapat dilihat pada tabel berikut :

Tabel 3 : Rekapitulasi Hasil Uji-t $N$-gain

\begin{tabular}{|l|l|l|l|l|}
\hline Jenis Data & Sig. (2-tailed) & $\alpha$ & Keputusan & Keterangan \\
\hline N-gain & 0.000 & 0.05 & Tolak $\mathrm{H}_{0}$ & Berbeda Signifikan \\
\hline
\end{tabular}

Berdasarkan Tabel 3 diperoleh nilai Sig. (2-tailed) untuk data N-gain pada kelas kontrol dan kelas eksperimen adalah $0.000<0.05$ dengan keputusan tolak $\mathrm{H}_{0}$ yang artinya terdapat perbedaan yang signifikan antara $\mathrm{N}$ gain kelas kontrol dan kelas eksperimen.

\section{KESIMPULAN}

Berdasarkan hasil penelitian yang telah dilakukan di SMA Negeri 16 Pekanbaru dapat disimpulkan bahwa penggunaan model pembelajaran Group Investigation dengan pendekatan Jelajah Alam Sekitar berpengaruh terhadap hasil belajar siswa pada materi Plantae
Terjadinya peningkatan hasil $\mathrm{N}$ gain menunjukkan terjadinya peningkatan hasil belajar pada materi Plantae. Nilai N-gain kelas eksperimen yang menggunakan model pembelajaran Group Investigation dengan pendekatan Jelajah Alam Sekitar lebih tinggi dibanding dengan kelas kontrol dengan menggunakan metode konvensional.

kelas X SMAN 16 Pekanbaru tahun pelajaran 2018/2019.

\section{SARAN}

Berdasarkan penelitian yang telah penulis lakukan, maka penulis menyampaikan saran-saran sebagai berikut : 
a. Kepada guru, terutama guru biologi agar dapat menggunakan model pembelajaran Group Investigation dengan pendekatan Jelajah Alam Sekitar karena mampu meningkatkan hasil belajar siswa.

b. Bagi peneliti, diharapkan agar menyediakan bahan pembelajaran sebagai persiapan apabila ada salah satu dari kelompok tidak menemukan tumbuhan yang telah ditentukan, serta mengawasi dan mengingatkan siswa untuk tetap menjaga ketentraman lingkungan sekolah baik mulai dari pembentukan kelompok hingga siswa keluar kelas untuk melakukan penyelidikan di alam sekitar.

\section{DAFTAR PUSTAKA}

Abdurrahman, M. (2010). Pendidikan Bagi Anak Berkesulitan Belajar. Rineka Cipta : Jakarta.

Arikunto, S. (2011). Prosedur Penelitian. Bumi aksara : Jakarta.

Aryulina D, Muslim C, dan Syalfinah Manaf. (2007). Biologi 1 SMA dan MA Untuk Kelas X. Jakarta : Erlangga.

Brainly. (2014). Siklus Hidup Gymnospermae [online]. Tersedia https://brainly.co.id/tugas/48288_[16

Oktober 2018].
Dimyati \& Mudjiono. (2015). Belajar dan Pembelajaran. Rineka Cipta : Jakarta.

Djamarah \& Zein, A. (2002). Strategi Belajar Mengajar. Rineka Cipta : Jakarta.

Faujiah, Suhada, dan Hartati. (2017). Penerapan Model Pembelajaran Group Investigation Terhadap Hasil Belajar Siswa Pada Materi Sistem Ekskresi Manusia. Vol 7. No 1[1-12].

Frankel \& Wallen. (1993). How to Desaign and Evaluate Researc In Education : McGRAW-HIL. Singapure.

Hamalik, O. (2009). Proses Belajar Mengajar. Bumi Aksara : Jakarta.

Hasmiati. (2017). Aktivitas Dan Hasil Belajar Siswa Pada Pembelajaran Pertumbuhan Dan Perkembangan Dengan Metode Praktikum. Vol 5. No 1 [21-33].

Janawi. (2013). Metodologi dan Pendekatan Pembelajaran. Ombak : Yogyakarta.

Jumiati, Mariana, dan Marta Dinata. (2016). Penerapan pendekatan Jelajah Alam Sekitar Berbasis Praktikum terhadap Penguasaan Konsep pada Mata Kuliah Morfologi Tumbuhandan Ekologi Tumbuhan Di FKIP Universitas Lancang Kuning. Vol 3. No 2 [106-116].

Meltzer, D.E. (2002). “The Relationship Between Mathematics Prepartion and Conceptual Learning Gains in Physics: Posisible "Hidden Variable" In Diagnostic Pretes 
Scores". American Journal of Physics. 70(7).

Nurjanah S, Suratno, dan Sulifah. (2014). Pengaruh Model Pembelajaran Student Team Achievement Division Dengan Metode Praktikum Terhadap Aktivitas dan Hasil Belajar Siswa Kelas XI SMA Negeri 1 Purwoharjo-Banyuwangi TP 2011/2012. Vol 3 No 1 [1-14].

Ridlo, S. (2005). Pendekatan Jelajah Alam Sekitar (JAS) Dipresentasikan pada Seminar dan Lokakarya Pengembangna Kurikulum dan Desain Inovasi Pembelajaran. JurusanBiologiF MIPAUNNES : Semarang.

Sardiman. (2006). Interaksi dan Motivasi Belajar Mengajar. Raja Grafindo Persada : Jakarta.

Sari, NM dan Eurika, N. (2016). Penerapan Model Pembelajaran Group Investigation Untuk Meningkatkan Hasil Belajar Siswa. Vol 1. No 1 [29-41].

Sasrawan, H. (2014). Kingdom Plantae [online]. Tersedia http://hedisasrawan.blogspot.com/ 2014/04/kingdom-plantae-artikellengkap.html (11 November 2018).

Slameto. (2003). Belajar dan FaktorFaktor yang Mempengaruhinya. Rineka Cipta : Jakarta.

Slavin. (2005). Cooperative Learning Teori Riset dan Praktik. Nusa Media : Bandung.
Sudirman. (2007). Aktivitas Belajar. Sinar Baru Alensindo : Bandung.

Sudjana, N. (2005). Media Pengajaran. Sinar Baru : Bandung.

Sudjana, N. (2009). Dasar-Dasar Proses Belajar Mengajar. Sinar Baru : Bandung.

Sugiyono. (2008). Statistika Untuk Penelitian. Alfabeta : Bandung .

Susanto. (2013). Reproduksi Gymnospermae dan Angiospemae [online]. Tersedia http://kumpulanperbedaan.blogspot.com/2013/08/ reproduksi-gymnospermae-danangiospermae.html [16 Oktober 2018].

Tatang. (2012). Ilmu Pendidikan. Pustaka Setia : Bandung.

Trianto. (2010). Model pembelajaran Inovatif. Gramedia : Jakarta.

Wikipedia. (2004). Bunga [online]. Tersedia https://id.wikipedia.org/wiki/Bung a (16 Oktober 2018).

Wulandari, A. (2010). Metode Penelitian [online]. Tersedia http://www. Trinoval. web.id.200/04/jenis-ujistatisti.html (30 September 2018).

Yamin, M. (2007). Paradigma Pendidikan Konstruktivisik. Gaung Persada Pers : Jakarta.

Yasa, D. (2008). Prestasi dan Aktivitas Belajar. Bumi Aksara : Jakarta 